\title{
EDITORIAL
}

\section{Health threat of global warming}

Global warming $(\mathrm{GW})$ has become one of the most visible environmental concerns of the twenty first century. ${ }^{1}$ It endangers human health, affecting several sectors of society, both domestically and globally. The consequence depends on the magnitude and rate of warming, geographic location, levels of development and vulnerability and on the implementation of adaptation and mitigation options. The largest effects are projected for low and middle income regions (African Continent, Southeast Asia and Latin America). Although an international climate agreement was approved at Paris conference (COP21, 2015) but lot of constraints still remains unaddressed. ${ }^{2}$

Every year, Bangladesh is exposed to a multitude of natural hazards such as floods, cyclone, tidal surges, droughts, riverbank erosion, etc. Simultaneously, adverse impact of ongoing climate change (CC) is emerging. According to a report on 'South Asia's Hotspots' (World Bank, 2018) more than 75 percent of the country population will be adversely affected by rising temperatures. Over the past few decades, Bangladesh has made significant advancements in health indicators, especially compared to other South Asian countries. ${ }^{3}$ However, climate change will have negative impact on these developmental milestones.

Human activities are estimated to have caused approximately $1.0^{\circ} \mathrm{C}$ of global warming above pre industrial levels, with a likely range of $0.8^{\circ} \mathrm{C}$ to $1.2^{\circ} \mathrm{C}$. $\mathrm{GW}$ is likely to reach $1.5^{\circ} \mathrm{C}$ between 2030 and 2050, if it continues to increase at the current rate. Estimated anthropogenic $\mathrm{GW}$ is currently increasing at $0.2^{\circ} \mathrm{C}$ (between $0.1^{\circ} \mathrm{C}$ and $0.3^{\circ} \mathrm{C}$ ) per decade due to past and ongoing emissions. ${ }^{4}$

Luxury emissions are different from survival emissions according to Lancet Commission (The Lancet, 2009), which emphasizes the need for a strategy of contraction and convergence, thereby rich countries rapidly reduce emissions and poor countries can increase emissions to achieve health and development gain, both having the same sustainable emissions per person.

The ocean has absorbed about $30 \%$ of the anthropogenic carbon dioxide, resulting in ocean acidification and changes to carbonate chemistry that are unprecedented in 65 million years which poses risk for the survival, growth and development of aquatic lives. 4 Global mean sea level rise is projected to be around 0.1 metre by 2100, which will continue to rise well beyond the century. A slower rate of sea level rise enables greater opportunities for adaptation in the human and ecological systems of small islands, low lying coastal areas and deltas.

Each of the last 3 decades has been successively warmer than any preceding decade since $1850 .{ }^{1}$ Climate change affects all the social and environmental determinants of health either directly or indirectly. The direct impacts will be an increased incidence of water and vector borne diseases, extreme heat and cold related diseases, and malnutrition. Indirect impacts will be visible in the increase of seasonal distribution of some allergic diseases and infections, fatal accidental injuries due to flood and landslides, mental and other illness.

Environmental effects can be summarized as follows.1,4 Extreme weather: In the heat wave of summer 2003 in Europe, more than 70,000 excess deaths were recorded. High temperatures also raise the levels of ozone and other pollutants in the air that exacerbate cardiovascular and respiratory disease. Populations at highest risk include older adults, children, women and those with chronic diseases; Natural disaster: Weather related disasters have more than tripled since the 1960s. More than half of the world's population live within $60 \mathrm{~km}$ of the sea and may be forced to move due to recurrent floods which contaminate freshwater supplies, heighten the risk of water borne diseases, and create breeding grounds for disease carrying insects. Previous IPCC (Inter Governmental Panel on Climate Change) reports confirmed the increased tropical cyclone, storm surges and coastal flooding due to GW. Rainfall patterns had also become more variable and erratic.

Food security: There is increasing evidence that high ambient levels of $\mathrm{CO}_{2}$ concentrations could affect human health by increasing the production and allergenicity of pollen and other compounds and by decreasing the nutritional quality of important food crops; Water security: GW is expected to substantially increase probability of drought and scarcity of water in some regions. Climate change could force more than 100 million people into extreme poverty, mostly through impacts on agriculture and food prices; Migration \& displacement: GW had a statistically significant effect on outmigration over recent decades in 163 countries particularly for agriculture dependent countries; Occupational health: $\mathrm{CC}$ is projected to increasingly compromise safe work activity and worker productivity during the hottest months of the year.

Climate change is expected to cause approximately $2,50,000$ additional deaths per year between 2030 and 2050; 38,000 due to heat exposure in elderly people, 48,000 due to diarrhoea, 60,000 due to malaria, and 95,000 due to childhood undernutrition. ${ }^{4} \mathrm{CC}$ is projected to be a poverty multiplier particularly for people living in small island, developing states and other coastal regions, megacities, and mountainous and polar regions.

The environmental consequences of Climate change, those already observed and those that are anticipated, will affect human health both directly and indirectly. 5 The Lancet Commission have focused on six aspects that connect $\mathrm{CC}$ to adverse health outcomes: changing patterns of disease and mortality, food, water and sanitation, shelter and human settlements, extreme events, and population and migration.

The series of health effect as highlighted in "A human health perspective on climate change" (IWGCCH, 2010) starts with: Asthma, Respiratory allergies and Airway diseases- Respiratory allergies and diseases may become more prevalent because of increased human exposure to pollen (due to altered growing seasons), molds (from extreme or more frequent precipitation), air pollution and aerosolized marine toxins (due to increased temperature, coastal runoff, and humidity) and dust (from droughts); Cardiovascular disease and strokeExisting cardiovascular disease may exacerbate by increasing heat stress and burden of airborne particulates; Cancer- Risk for cancer 
increases due to the potential direct effect of GW such as increased duration and intensity of ultraviolet radiation.

Heat related morbidity-Heat related illness and deaths are likely to increase in response to GW; Human developmental effects- Malnutrition and biotoxin exposure during prenatal period would adversely affect the human development; Mental health and Stress related disorders- CC may result in geographic displacement of populations, damage to property, loss of loved ones, and chronic stress, all negatively affecting mental health.

Foodborne diseases and nutrition- CC may be associated with staple food shortages, malnutrition, and food contamination (chemical contaminants, biotoxins, and pathogenic microbes and pesticides); Vectorborne and Zoonotic diseases- Disease risk may increase as a result of climate change due to related expansions in vector ranges, shortening of pathogen incubation periods and disruption and relocation of large human populations; Waterborne diseases- Increases in water temperature, precipitation frequency and severity and changes in coastal ecosystem would increase the incidence of water contamination with harmful pathogens and chemicals.

Air Pollution, as mentioned by Bouazza N (ADC, 2018), demands special attention. There is increasing epidemiological evidence of the association between air pollution and asthma exacerbations in children. Fine particles $<2.5 \mathrm{~mm}$ in diameter (PM2.5) can penetrate deep into the airways and induce alveolar inflammation. The Air Quality Guidelines set by the WHO are stricter than the EU air quality standards for PM2.5 which is 10 and $25 \mathrm{mg} / \mathrm{m} 3$ respectively. Young children with asthma are particularly susceptible to air pollution because of their developing lungs, immature metabolic pathways, high breathing rates per bodyweight and frequent exposure to outdoor air.

Environmental experts suggested that a shift from motorised transport to active travel (more walking and cycling) in cities will reduce traffic related NO2 and PM2.5, as well as carbon emissions and noise, providing multiple opportunities ('co benefits') for improved physical and mental health. It is less well known that respiratory drugs is making a sizeable contribution to global warming because of the propellant gases used in metered dose inhalers. Although hydrofluorocarbons do not deplete the ozone layer, they are powerful greenhouse gases. They have a global warming effect of up to 3800 times higher than that of carbon dioxide. Fortunately, dry powder inhalers could be a possible alternative for the delivery of respiratory drugs but it has some limitation as well.

The Environmental commission (The Lancet, 2009) noted that the biggest sociopolitical challenge affecting the success of climate change mitigation is the lifestyle of those living in rich nations and a small minority living in poor nations, which is neither sustainable nor equitable. Vertical links need attention: local action to prevent local flooding and global action to ensure proper funding. Horizontal coordination requires joint thinking across governments and international agencies.

Greenhouse gases and air pollutants are typically emitted by the same sources. ${ }^{3}$ Hence, mitigation strategies that reduce GHGs or the use of fossil fuels typically also reduce emissions of pollutants, such as particulate matter (PM2.5 and PM10), black carbon (BC), sulphur dioxide (SO2), nitrogen oxides $\left(\mathrm{NO}_{2}\right)$, and other harmful species, causing adverse health and ecosystem effects at various scales. Changing agricultural practices can be an effective climate adaptation strategy. Improving the efficiency of food production and closing yield gaps have the potential to reduce emissions from agriculture, reduce pressure on land and enhance food security and future mitigation potential.

Ideas of carbon capture in power stations, carbon taxes with $100 \%$ dividends for low carbon users, and fourth generational nuclear power are on the highest consideration. Setting up a global fund for loss and damage from climate change is necessary for disaster preparedness and adaptation. Funds beyond insurance should also be raised by taxing polluters. The principle of 'polluter pays' may be an effective way to mitigate GW. ${ }^{2}$

The 1.5 Health Report makes clear that the lower the warming, the safer it is for health. "Decarbonising our lives" is entirely possible and will make this world a healthier, more prosperous and sustainable place. 5 An integrated and multidisciplinary approach to reduce the adverse health effects of climate change requires at least three levels of action. First, policies must be adopted to reduce carbon emissions and to increase carbon biosequestration, and thereby slow down global warming and eventually stabilise temperatures. Second, action should be taken on the events linking climate change to disease. Third, appropriate public health systems should be put into place to deal with adverse outcomes.

In Bangladesh, climate change may result in possible dreadful consequences in near future, particularly for the communities located in the most vulnerable zones where their livelihoods will not be sustainable for long. 3 Govt. of Bangladesh has already initiated the 'Nationwide Climate Vulnerability Assessment' to develop an evidence based tool for prioritizing adaptation funding and intervention within the country. The primary assessment demonstrates that, the exposure to climate change is increasing; the sensitivity is also increasing; but the adaptive capacity is low. Thus it is urgently needed to consider adaptation now in order to become resilient in the coming years.

CH Rasul, Professor of Paediatrics (Rtd), KMC\&:H; Email: chrasulayahoo.com

\section{References:}

1. WHO. Climate change and health. 01 February 2018. http://www.who.int/news-room/factsheets/detail/ climate change and health

2. Huq S. Politics of climate change - Thinking outside the box. The Daily Star, 09 September 2018

3. Ministry of Environment, Forest and Climate Change, Government of the People's Republic of Bangladesh and GIZ. Nationwide Climate Vulnerability Assessment in Bangladesh. Dhaka. November 2018

4. IPCC. Global warming of $1.5^{\circ} \mathrm{C}$ Summary for policy Makers. 48th session of IPCC, Incheon, Republic of Korea. 06 October 2018

5. Balakrishnan VS. Global warming: Experts demand urgent action to prevent public health crisis. BMJ 2018; 363: K 4241 